\title{
Desincronización temporal y espacial entre trabajo y familia: Hacerse el salario en las migraciones estacionales de los/as temporeros/as de la uva
}

\author{
Ximena Valdés Subercaseaux ${ }^{1}$ \\ Universidad de Santiago, Santiago, Chile. Email: ximenavaldess@gmail.com
}

\begin{abstract}
Resumen: La movilidad y las migraciones estacionales forman parte del mercado de trabajo que genera la agricultura y agroindustria de exportación. Este estudio se localiza en Atacama, la región más especializada en uva de mesa de exportación, y que es, la actividad que paga mejores salarios en comparación con el resto de las frutas y que insume más trabajadores por hectárea. El artículo analiza el uso del tiempo laboral anual de los trabajadores para conocer las migraciones, los ingresos de los/as temporeros/as que trabajan en algún momento del año en el valle de Copiapó, el tipo de ocupación, y los lugares en que las realizan. El corpus del estudio consiste en entrevistas grupales e individuales a temporeros de ambos sexos, distintas edades, etnias y nacionalidades que trabajan en el valle de Copiapó. El estudio busca comprender las consecuencias que produce la deslocalización del trabajo con respecto de la residencia en las familias. Los trabajadores y trabajadoras extienden los tiempos de trabajo desplazándose a través de diferentes faenas agrícolas en el territorio nacional, así como a través de migraciones transfronterizas. El sexo y la situación familiar, lo social (pauperización de las economías campesinas e indígenas, desempleo, bajos salarios en los lugares de residencia) explicarían distintos patrones migratorios por sexo y edad.
\end{abstract}

Palabras clave: trabajo, familia, migraciones

\section{Temporal and spatial desynchronization among work and family: Making your salary in seasonal migration of grape harvest temporary workers}

\begin{abstract}
Mobility and seasonal migrations are part of the labour market that generates agriculture and the export sector of agroindustry. Fruits and specially grapes demand many workers, male and female, during the crops period. This study was made in the Region of Atacama, mainly in the Copiapó Valley. This area is special for the production of grapes for international markets. In this area, salaries and wages are better than in other fruit activities. Also the grapes activities need a lot of labor working in short term periods. Many people come year by year to the Copiapó Valley for the period of crops. This paper studies the use of the annual working period of temporary workers, to understand migration mobility, the incomes of those who at some time of the year work here, the kind of jobs they undertake and the places where they carry them out. The corpus of this paper are individual and group interviews to temporary workers of different ages, gender , ethnic and national origin, in the Valley of Copiapó. The study wants to understand the consequences of this kind of temporary jobs in the unity and composition of the families. Workers, male and female, transit through many different agricultural activities in different parts of the territory. as well as across borders. Sex, family situation, social conditions (poverty of peasant and indigenous economy, unemployment, low salaries in their places of residence) explain different patterns of migrations for sex and age.
\end{abstract}

Key words: work, family, migrations

\section{Dessincronização temporal e espacial entre trabalho e família: Torne-se salários na migração sazonal dos/as operarios/as temporários/as da uva}

Resumo: A mobilidade ea migração sazonal são parte do mercado de trabalho gerada pelas exportações da agricultura e do agronegócio. Este estudo está localizado no Atacama, a região especializada na exportação de uvas de mesa, e que é, a atividade que paga salários mais altos em comparação com outras frutas e consumindo mais trabalhadores por hectare. $\mathrm{O}$ artigo discute o uso do tempo de trabalho anual dos trabalhadores para conhecer sobre a migração, renda dos/as temporários/as que trabalham em algum momento do ano no vale de Copiapó, o tipo de ocupação, e os lugares onde o executada. O corpus do estudo é de grupo e entrevistas individuais para temporário de ambos os sexos, de diferentes idades, etnias e nacionalidades que trabalham no vale de Copiapó. O estudo procura compreender as conseqüências produzidas pela deslocalização do trabalho a partir da residência de famílias. Trabalhadores estendem o tempo de trabalho através da rolagem do diferente trabalho agrícola no país, e através de migração transfronteiriça. Sexo e situação familiar, social (empobrecimento das economias camponesas e indígenas, o desemprego eos baixos salários em locais de residência) explicam diferentes padrões de migração por sexo e idade.

Palavras-chave: trabalho, família, migração, 


\section{Introducción}

El empleo temporal en la agricultura chilena no es nuevo. Tampoco lo es el trabajo estacional e itinerante (Falabella, 1970; Santana, 1980; Salazar, 1986) que comportó desplazamientos geográficos desde áreas de pequeña propiedad, aldeas y pueblos a fundos y haciendas. Sin embargo, hasta la reforma agraria, este segmento de trabajadores era minoritario y a la vez masculino. Hoy en cambio, en una agricultura fuertemente orientada al mercado externo, el empleo temporal nutre mayoritariamente el mercado de trabajo y es más gravitante en la fruticultura de exportación que goza de una minoría de trabajadores con empleo estable, fundamentalmente hombres mientras entre los asalariados temporales más de un tercio son mujeres que a la vez acusan movilidad espacial ya que las migraciones estacionales, así como la composición por sexo de este mercado laboral, se han feminizado (Valdés, 1988, 1992, 2010). Ante tales transformaciones, nos preguntamos sobre sus impactos en la familia.

Varios autores (Gómez, 2001; Kay, 2009) se refieren a la nueva ruralidad incorporando como sus atributos el empleo temporal, propio de las agriculturas globalizadas latinoamericanas. La feminización del mercado de trabajo, las migraciones estacionales y la creciente incorporación de poblaciones urbanas a los empleos que genera la producción de frutas para la exportación, figuran entre los rasgos de los espacios rurales que han internacionalizado su producción a través de empresas agroindustriales nacionales y multinacionales. Otros autores, remarcan estos fenómenos así como la generización de cierto tipo de empleo en la fruticultura y el visible desplazamiento de mujeres y familias en los territorios para hacerse de un salario en la fruta y las hortalizas (Lara, 2010; Valdés, 2010) cubriendo así fenómenos vinculados a la crisis de las economías campesinas e indígenas, el desempleo urbano y rural, el incremento de las familias monoparentales con jefatura femenina. En Chile como en otros países de la región (Lara, 2010), el empleo temporal agrícola figura entre los más precarios y el que muestra más baja remuneración en el conjunto del empleo generado por las actividades de exportación ${ }^{2}$. Estos regímenes de trabajo se caracterizan por su estacionalidad; en ciertos períodos del año por la larga extensión de la jornada laboral que afecta más a mujeres que a hombres. Las formas de reclutamiento de los/as temporeros es en forma directa o a través de subcontratistas. Esto último agudiza la precarización laboral (Caro et al., 2009) favoreciendo los desplazamientos geográficos de los/as temporeros/as. Las formas de remuneración están orientadas por el rendimiento por tarea bajo la norma de pago "a trato". Así, por un lado la economía configura un determinado mercado de trabajo determinando el tipo de empleo, su duración y calidad; por otro, los trabajadores/as despliegan distintas modalidades para constituir sus ingresos salariales habida cuenta de la inestabilidad laboral y del carácter estacional de las labores frutícolas.

En cuanto a la composición por sexo de la fuerza de trabajo temporal en la fruticultura, la CASEN 2006 y 2009 muestran la disminución de los empleos estables masculinos y el engrosamiento de la franja de trabajadores hombres temporales junto al creciente aumento de mujeres en el empleo temporal mientras se mantiene en el trienio una muy baja proporción en los empleos permanentes de sexo femenino.

Tal característica y evolución del mercado de trabajo plantea un sinnúmero de problemas para la reproducción de la sociedad pues estas modalidades de trabajo imprimen cambios en las familias y las relaciones de género, desde la incorporación del salario femenino hasta el distanciamiento de las mujeres de los hogares cotidiana y estacionalmente. La erosión de la figura del padre-esposo proveedor que va perdiendo su inserción laboral estable en el trabajo, el doble salario femenino y masculino, modifican los patrones de autoridad en la familia (Valdés, 2007). La contratara de este proceso de precarización laboral masculina es entonces la entrada de mujeres al trabajo asalariado de temporada.

\section{Problema y enfoque}

Hoy en la fruticultura predomina lo que algunos autores describen como "trabajo sin calidad" (Sennet, 2000), precario (Castel, 1995), desregulado y flexible, generador de mayor incertidumbre (Castel, 2009), 
alejado de las seguridades que proporcionó el vínculo laboral estable, en el límite de colocar a los trabajadores en el riesgo de la exclusión (Beck, 1998) pero más bien en situaciones a medio camino entre la integración y la exclusión que están a la raíz de la vulnerabilidad social (Castel, 1995).

En este marco de mutaciones del campo laboral, tanto el capital como la fuerza de trabajo no tienen fronteras (Sassen, 2003, 2009). La movilidad geográfica y las migraciones laborales se inscriben en los procesos globalización, flexibilidad laboral y feminización del empleo (Maruani, 2000). Tales fenómenos se alimentan del incremento de las incertidumbres causadas por la inestabilidad laboral bajo un telón de fondo de fragilización de las protecciones sociales brindadas por el Estado de Bienestar (Castel, 2009) que, en Chile, se encarnaron para los trabajadores agrícolas en las leyes laborales de 1953 y aquellas que acompañaron a la reforma agraria 1964-73, luego desmanteladas y reformuladas a partir de la contra-reforma y las legislaciones laborales posteriores.

Actualmente hombres y mujeres se insertan en un mercado de trabajo frutícola pugnando por escapar al proceso diseñado hace algunas décadas de "salarización de la pobreza" (Díaz, 1991). La inclusión precaria e inestable en el empleo deriva en que no es el empleo el que incluye a los trabajadores de manera estable sino son los trabajadores los que deben buscar trabajo desplazándose de empresa o lugar a objeto de prolongar el tiempo de salarización para generar mayor frecuencia de ingresos. Migraciones y movilidad forman parte de las nuevas modalidades de constituir el salario y a la vez, factores que interfieren en la organización, composición, relaciones sociales de género en la familia (Lesnard, 2009). La relación trabajo-familia, en la medida que produce deslocalización de la residencia con respecto al lugar de trabajo a distancias considerables, es una evidencia de las consecuencias en la familia y la reproducción de la sociedad del proceso desencadenado con la reorganización del empleo (ibid). La fuerza de trabajo temporal agrícola se ha feminizado (Valdés, 1988, 1992, 2007) como lo han hecho las migraciones laborales (Stefoni, 2002) motivadas por la búsqueda de empleos mejor remunerados que los que hay en los lugares de residencia, lo que en particular incluye a jefas de hogar en la región de Atacama (Valdés y Godoy, 2005).

La reorganización del trabajo evidencia el abandono del mundo laboral que caracterizó la sociedad salarial (Castel, 1995) construida al alero de los Estados de Bienestar cuyos sistemas de regulación lograron establecer las 8 horas de trabajo como la jornada laboral normal y donde no fue frecuente la disociación a grandes distancias entre trabajo y lugar de residencia. Aunque en la agricultura, el trabajo estacional y migratorio formó parte de las distintas categorías de trabajadores ya que la figura del afuerino y del peón itinerante acompañó la historia social del campo chileno y sus actividades estacionales, lo nuevo es que hoy se ha feminizado ${ }^{3}$, que involucra a población urbana y rural ${ }^{4}$, que contempla mayores distancias y que incorpora poblaciones de países andinos ${ }^{5}$ y población indígena ${ }^{6}$.

A diferencia de la organización del trabajo del período de industrialización hasta la reforma agraria donde hubo una proporción mayor de trabajadores agrícolas con empleo estable y formal ${ }^{7}$, en economías globalizadas como las actuales, regidas por la flexibilidad laboral, el principio organizador basado en un importante contingente de trabajadores estables, en su mayoría hombres, hoy no rige ni el funcionamiento del mercado de trabajo ni tampoco implica, a nivel familiar, la separación de esferas laborales para hombres y domésticas para las mujeres ${ }^{8}$. Un nuevo orden de género alejado del principio del "salario familiar y la maternidad moral" (Goody, 2002) ganó terreno en las economías globalizadas del capitalismo tardío. La ausencia de las mujeres de hogares con hijos, por su papel en la reproducción, abre interrogantes frente a las maneras de encarar períodos largos de migración y jornadas laborales que se extienden a altas horas de la madrugada en los meses estivales.

En este marco de transformaciones del trabajo, el modelo de familia de la sociedad salarial también ha sido testigo de cambios. Entre las más importantes el estancamiento del proceso de nuclearización, el aumento de las familias monoparentales con jefatura femenina, la informalización del lazo conyugal-matrimonial, el aumento de las separaciones y divorcios, el que la mayoría de los hijos nazcan fuera del matrimonio, entre otros (Valdés, 2007). En concordancia con esta metamorfosis ocurrida en la familia y del alejamiento del modelo a la que apostó la sociedad salarial de "familia conyugal", hoy se habla de "la familia en desorden" (Roudinesco, 2004), "incierta" (Roussel, 1989) aunque estos síntomas se refieran al proceso que afecta a la familia conyugal y que su des-institucionalización, visible en indicadores de caída de la nupcialidad y la fragilidad del lazo conyugal conviva con el reforzamiento -a nivel jurídico como social- de los lazos de 
parentesco y filiación (Théry, 1998, 2002, 2005). Estas transformaciones de orden demográfico extendidas en las sociedades contemporáneas, se acompañan por el debilitamiento de las protecciones sociales de la sociedad salarial constituida en el siglo XX y han contribuido a desplazar las funciones protectoras del Estado de Bienestar a la "sociedad de bienestar" donde el sistema de parentesco y los vínculos de proximidad actúan como sistema de protección social (Souza dos Santos, 1998).

Así entonces, tanto el campo laboral como el familiar, soportes fundamentales en la vida de las personas y del establecimiento de lazos sociales, son testigo de procesos de informalización y precarización con el alejamiento por un lado de la jornada laboral de 8 horas y de la estabilidad en el empleo; por otro, por la inestabilidad e informalidad del lazo conyugal. Tales procesos están a la raíz de la aparición de nuevas formas de vida en común o del aumento de otras que siendo conocidas hoy tienen mayor significación (Valdés, 2007).

Este tipo de transformaciones sociales que se agolpan bajo nuevos modelos de acumulación y funciones del Estado modificando el campo laboral y familiar implican revisar los marcos analíticos que sostienen que la división sexual del trabajo en la familia explica lo que ocurre en el mundo del trabajo sino proceder al revés, analizando en paralelo cómo el mundo del trabajo interfiere en el modo en que se organiza la familia, para comprender cómo lo que ocurre en la esfera productiva/pública otorga elementos para comprender lo que ocurre en la esfera reproductiva/privada ya que el ámbito laboral interfiere en la familia, en la división sexual del trabajo doméstico, el sistema de autoridad y poder en la vida privada. Esto ha llevado a revisar los análisis en una sola dimensión -familia/trabajo- y a adoptar el estudio de la relación inversa: trabajo/familia. Más que analizar cómo la familia y la situación de hombres y mujeres en ella explican el modo en que ambos sexos se insertan en el mercado de trabajo, hay que analizar cómo el mercado de trabajo explica lo que ocurre en la esfera doméstica y la familia (Alonzo, Angeloff y Maruani 2005).

En este contexto, la flexibilidad laboral y los regímenes excepcionales de trabajo que contemplan ampliación de la jornada laboral, deslocalización del trabajo con respecto de la residencia, migraciones, feminización del mercado laboral, movimientos de población de ambos sexos en búsqueda de empleo, contribuyen a la desarticulación familiar (Lesnard, 2009), lo que pone de relieve las consecuencias de la economía en la familia y el hecho de que la familia es producida por la sociedad que habita (Comaille y Martin, 1998).

\section{Metodología}

Hay autores que han puesto el acento en la complejidad del fenómeno migratorio proponiendo el análisis del punto de partida y punto de llegada -emigración-inmigración- para comprender cómo la migración interfiere a nivel comunitario y familiar. Comunitarismo e individualismo diferenciarían a las generaciones entre los primeros migrantes y los hijos/as nacidos en los países de acogida (Abdelmalek, 2006). Estudiando la misma área geográfica -Argelia-Francia-, Aldelhafid (2007) analiza cómo el fenómeno migratorio expone a los migrantes del Mahgreb al modelo de familia nuclear con el distanciamiento de la aldea argelina por la "recomposición cultural" que se produce en el lugar de instalación. En Latinoamérica, las migraciones que afectan las áreas rurales son crecientemente estudiadas como fenómenos propios del siglo XXI que afectan a indígenas, mujeres y familias (Canales, 2006) comprendiendo migraciones internacionales, transfronterizas e internas a distintos países. Se ha recurrido a con métodos cuantitativos -análisis intercensaly cualitativos para analizar el fenómeno migratorio. Otros autores lo han estudiado a través del método genealógico (Lara, 2010) siguiendo como en los casos anteriores a varias generaciones desde comunidades indígenas, el noroeste mexicano y Estados Unidos.

En nuestro caso de inmigración reciente, ya que las plantaciones de parronales datan de los años ochenta, hemos optado por una metodología que radica en el análisis del uso del tiempo laboral a lo largo del año en la temporada agrícola 2009-2010. Sobre la base de entrevistas grupales e individuales a temporeros de ambos sexos, nacionalidades y origen étnico, aplicadas en lugares de trabajo y de residencia a migrantes al valle de Copiapó y desde el valle de Copiapó a otros lugares ${ }^{9}$, analizamos la movilidad espacial y migraciones, entendiendo que éste es uno de los reveladores de la reorganización del trabajo y de la manera en que se conforma el salario. Privilegiamos a las mujeres en cerca de dos tercios de los casos, sabiendo que 
se trata de conocer las consecuencias de estas formas de organización del trabajo en la familia y que son ellas bajo los actuales patrones de género y división sexual del trabajo doméstico, los pilares de la misma.

\section{El valle de Copiapó en la región de Atacama}

De tradición minera que aún conserva, con una agricultura orientada al mercado interno hasta la década del setenta, en los años ochenta se instalan grandes empresas trasnacionales y nacionales ${ }^{10}$ que producen también en la zona mediterránea del valle central chileno uva de exportación. Se expande la frontera agrícola por la introducción de riego por goteo y se asiste a la reconversión productiva de las grandes y medianas explotaciones a las plantaciones de uva para exportación y olivares para la fabricación de aceite.

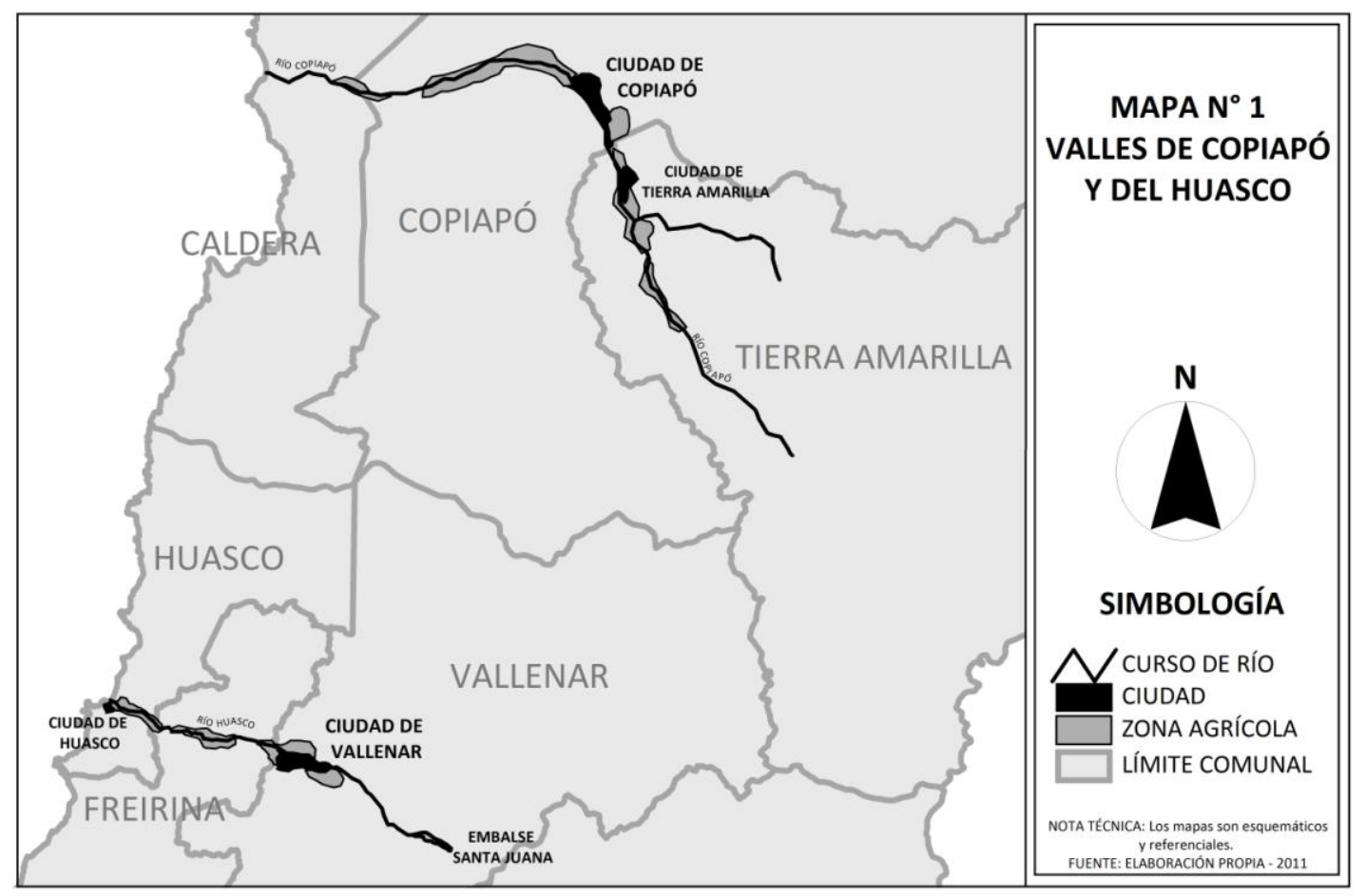

El empleo se organiza anualmente conforme duran labores que implican faenas en las plantaciones de parronales, durante invierno y primavera "en seco" (poda y amarra) y "en verde" (raleo, cepillado, etc.). Estas son seguidas por las labores de verano: cosecha seguida de limpieza y embalaje en las plantas agroindustriales. Una parte de los temporeros/as se desplaza entre valles para mantener el salario varios meses. Así como llegan trabajadores/as de afuera, otros/as que son residentes migran a los valles meridionales. Prolongar el tiempo de salarización, reviste mayor importancia entre quienes deben mantener a sus familias: hombres con hijos y mujeres con hijos jefas de hogar ${ }^{11}$ aunque temporeras/os jóvenes se desplacen estacionalmente para ahorrar gastos a sus familias o porque están en edades de asumir su independencia económica. Dado que la maduración de la uva es más temprana en el valle de Copiapó que en los valles de más al sur, los desplazamientos de trabajadores/as confluyen a comienzos de la temporada a este valle desde distintas regiones de Chile y de los países andinos. Sumados a población residente, se desplazan hacia valles meridionales una vez terminadas las faenas de la uva en Copiapó a mediados de febrero.

Según el último Censo Agrícola Ganadero, la curva de empleo y la proporción por sexo de trabajadores temporales varía en el año, lo que modula el ritmo del empleo local y de las migraciones por sexo, siendo el principal aliciente para las mujeres las labores de packing que se realizan entre diciembre y comienzos de febrero y para los hombres las faenas "en seco" y "en verde" entre invierno y verano, a las cuales se incorporan crecientemente mujeres. 
Figura $\mathrm{N}^{\circ} 1$ : Atacama, ciclo anual del empleo agrícola temporal por sexo

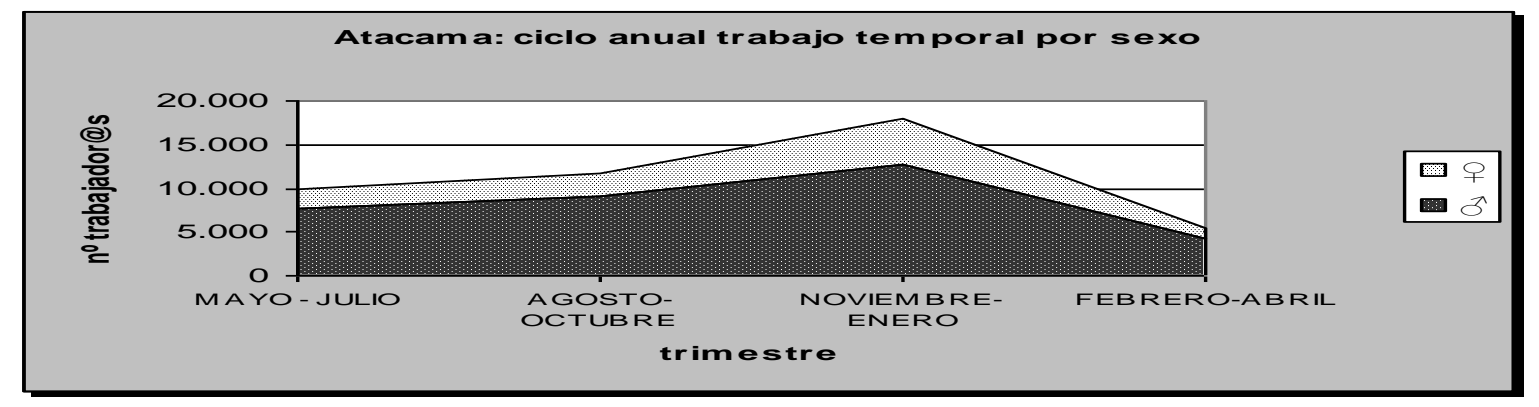

Fuente: en base a datos Censo Agrícola ganadero 2007, INE, Santiago.

También en Atacama, los regímenes laborales en la uva se caracterizan por una baja proporción de trabajadores estables, mayoritariamente hombres y una proporción mayor de asalariados temporales de ambos sexos. Los primeros tienen contratos indefinidos que garantizan empleo estable y suelen habitar al interior de las empresas mientras los segundos tienen contratos por faena o unidad de medida. Los salarios varían entre los temporeros según la productividad del trabajo lo que tiene como consecuencia el alargamiento de la jornada laboral por encima de la jornada de 8 horas, extendiéndose a más horas en el proceso de limpia y embalaje en los packing que en las faenas "en seco" y "en verde" en el potrero.

Movilidad espacial y migraciones a las faenas de la uva

Las empresas agroindustriales, más de un centenar en el valle de Copiapó ${ }^{2}$, contrataron en la temporada 2004-2005 a un 60\% de trabajadores migrantes mientras el $40 \%$ fue fuerza de trabajo local. Entre los asalariados hombres hubo un $90 \%$ migrantes - de tradición minera los copiapopinos son renuentes a trabajar en la fruta - y en el total de las mujeres, sólo el 50\% no residía en el valle (Valdés y Godoy, 2005).

Según lo encontrado en las entrevistas realizadas la temporada 2009/2010, a las migraciones estacionales de hombres y mujeres se agregan las definitivas al valle de mujeres chilenas ${ }^{13}$, además de peruanos y ecuatorianos de ambos sexos, sabiendo que en ellos siempre está en el horizonte volver a su país de origen ${ }^{14}$. Las migraciones laborales asumen modalidades que van desde los desplazamientos con y sin contratistas, individuales y colectivas, bajo la lógica de conseguir empleo directo en las empresas o lograrlo por medio de un agente de subcontratación. El papel de intermediario de fuerza de trabajo involucra a hombres y mujeres y, a mujeres que trabajan en las faenas y a la vez reclutan a otros/as temporeros/as. 


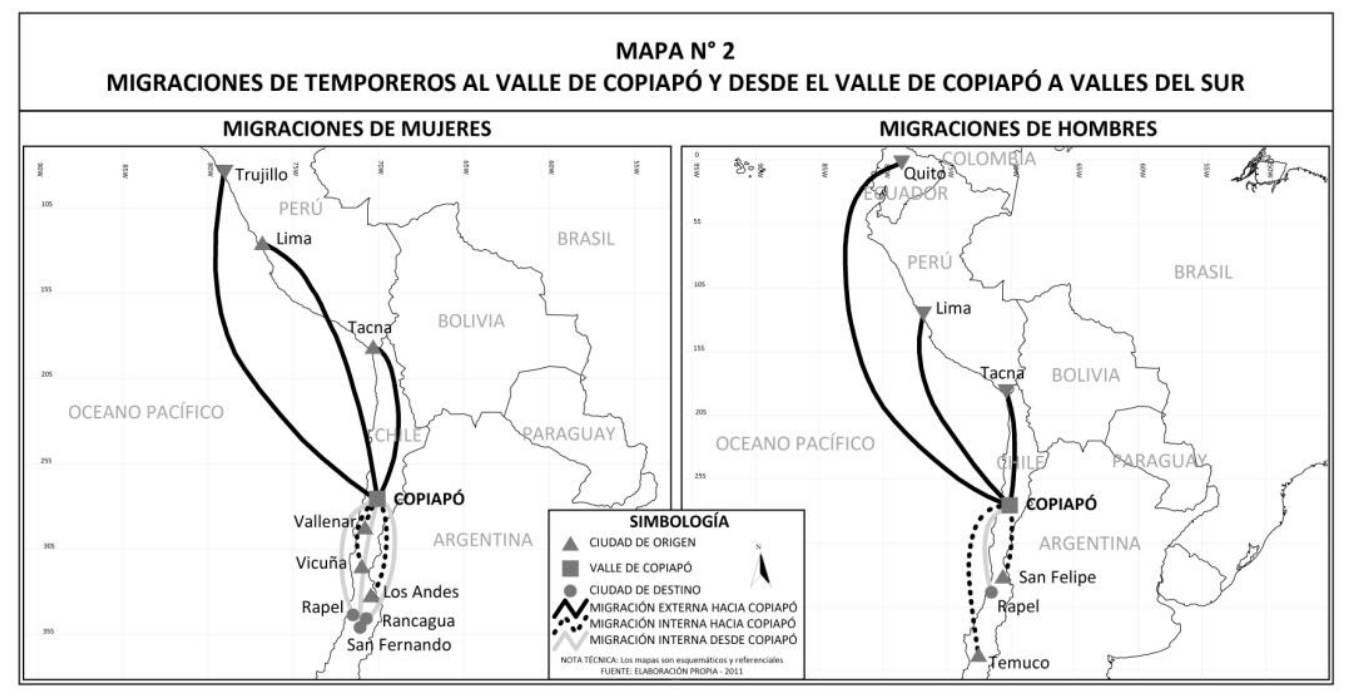

Entre los hombres se encontró desplazamientos levemente más largos que entre las mujeres: desde Quito (Ecuador), Lima y Tacna (Perú), la región de Valparaíso hasta la región de la Araucanía, (Chile). Las migrantes mujeres eran originarias de la Araucanía, de la región de Valparaíso y Coquimbo; de Arica en Chile, Trujillo y Tacna, en Perú. A diferencia de los chilenos, entre los extranjeros las migraciones si bien no definitivas tenían por resultado radicarse en Copiapó u otra ciudad del norte del país donde se desempeñaban en la construcción los hombres, la agricultura y el empleo doméstico las mujeres, para luego en la temporada de la fruta trabajar como temporeros en la uva. Hombres y mujeres originarios de países andinos tienden a permanecer en Copiapó varios años buscando lograr visa para trabajar. Las chilenas o migran para quedarse, o van a la temporada al igual que los temporeros hombres chilenos e indígenas. Los temporeros de ambos sexos son originarios del medio rural y urbano, obreros de la construcción y campesinos los hombres y obreras de la pesca, empleadas domésticas, estudiantes y "temporeras largas"15 las jefas de hogar. Esto quiere decir que por medio de las migraciones obtienen salario en la uva varios meses al año ya que se desplazan conforme va madurando la uva de norte a sur. Siguiendo las faenas de la uva en distintos valles se encontró tanto inmigración a Copiapó como emigración a la temporada de la uva desde residentes en Copiapó hacia valles de la región central de Chile en las que estaban involucradas mujeres de distintas edades y situaciones familiares no así mujeres con pareja e hijos. Los inmigrantes hombres siguen las faenas de raleo mientras las mujeres inmigrantes y emigrantes, las de packing, generalmente en la uva, lo que remite a una cierta especialización en esta labor -la mejor pagada dentro de la fruticultura-.

\section{Sexo, situaciones laborales y familiares de los/as temporeros/as migrantes}

Edades, estructuras y condiciones familiares, sexo, etnia y nacionalidad diferencian a los migrantes estacionales. Las características de la movilidad laboral asume distintas modalidades según edad, sexo y situación familiar:

\section{Versatilidad laboral de las temporeras jóvenes solteras sin hijos}

Entre las jóvenes, se encontró a obreras de la pesca -fileteo de pescado- (Arica), a estudiantes mapuche (Temuco), empleada doméstica (Trujillo) y contadora (Lima, su familia residente en el valle de Aconcagua). La independencia de la familia en términos económicos y domésticos, la contribución de las jóvenes al ingreso familiar, se encuentran entre los motivos para desplazarse a las temporadas y ganar un salario más alto que el que perciben donde viven, en ocupaciones pagadas en torno al salario mínimo. Menores de 30 años, sus motivaciones son ganar dinero y pasarlo bien, conocer gente y lugares. Dentro de sus trayectorias y proyectos de vida primaban los estudios y capacitación profesional. Las jóvenes mapuche estaban motivadas por trabajar para pagarse sus estudios universitarios; las jóvenes ariqueñas (chilenas y aymaras) en cambio por aumentar sus ingresos ya que en la pesca, como fileteadotas, sólo ganaban un salario 
mínimo. Las migraciones se hacían en grupos de amigas, compañeras de trabajo o de estudios mientras la inserción en estos empleos entre peruanas se hacían mediante contratistas y redes de compatriotas. No siempre trabajan en la uva el mes completo, por el tiempo de traslado y por factores asociados a la calidad de la uva.

GRÁFICO $\mathbf{N}^{\circ} 1$

JÓVENES SOLTERAS SIN HIJOS. OCUPACIONES Y LUGARES DE TRABAJO A LO LARGO DEL AÑO

\begin{tabular}{|c|c|c|c|c|c|c|c|c|c|c|c|c|}
\hline EDAD/ORIGEN & MAY & JUN & JUL & AGO & SEP & OCT & NOV & DIC & ENE & FEB & MAR & ABR \\
\hline \multicolumn{13}{|l|}{ Marilú, 28 años } \\
\hline Trujillo, Perú & & \multicolumn{6}{|c|}{ Faenas uva en seco y verde Copiapó } & \multicolumn{3}{|c|}{ Packing Copiapó } & \multicolumn{2}{|c|}{ Packing Valles sur } \\
\hline \multicolumn{13}{|l|}{ Milagros, 27 años } \\
\hline Lima, Perú & \multicolumn{6}{|c|}{ Comercio ambulante } & \multicolumn{3}{|c|}{ Packing Copiapó } & \multicolumn{3}{|c|}{ Packing valles sur } \\
\hline \multicolumn{13}{|l|}{ Maricel, 27 años } \\
\hline Arica, Chile & \multicolumn{4}{|c|}{ Obrera faenadora pescado Arica } & \multicolumn{2}{|c|}{$\begin{array}{c}\text { Faenas uva "en } \\
\text { verde" }\end{array}$} & \multicolumn{3}{|c|}{ Packing Copiapó } & \multicolumn{3}{|c|}{ Packing valles sur } \\
\hline \multicolumn{13}{|l|}{ Paula, 27 años } \\
\hline Arica, Chile & \multicolumn{4}{|c|}{ Obrera faenadora pescado Arica } & \multicolumn{2}{|c|}{$\begin{array}{c}\text { Faenas "uva en } \\
\text { verde" }\end{array}$} & \multicolumn{3}{|c|}{ Packing Copiapó } & \multicolumn{3}{|c|}{ Packing valles sur } \\
\hline \multicolumn{13}{|l|}{ Judith, 27 años } \\
\hline Arica, Chile & \multicolumn{5}{|c|}{ Obrera faenadora pescado Arica } & \multicolumn{2}{|c|}{$\begin{array}{c}\text { Faenas uva "en } \\
\text { verde" }\end{array}$} & Packir & Copiapó & \multicolumn{3}{|c|}{ Packing valles sur } \\
\hline \multicolumn{13}{|l|}{ Viviana, 29 años } \\
\hline Temuco, Chile & \multicolumn{7}{|c|}{ Estudios universitarios Temuco } & \multicolumn{3}{|c|}{ Packing Copiapó y pasas } & \multicolumn{2}{|c|}{ Estudios Temuco } \\
\hline \multicolumn{13}{|l|}{ Valeria, 23 años } \\
\hline Temuco, Chile & \multicolumn{7}{|c|}{ Estudios universitarios Temuco } & \multicolumn{3}{|c|}{ Packing Copiapó y pasas } & \multicolumn{2}{|c|}{ Estudios Temuco } \\
\hline
\end{tabular}

Peruana, hija de madre viuda, la mayor de tres hermanos, Marilú trabajó hasta los 23 años para ayudar a su familia con lo cual su hermana estudió en la universidad. Con estudios secundarios incompletos, trabajó en Perú siete años como empleada doméstica en ciudades de la selva y la sierra; se vino a Chile con otros peruanos hace dos años “como para conocer". El primer año trabajó como empleada doméstica en Copiapó "para tener contrato de trabajo y visa". Recorrió varios lugares trabajando por tiempos cortos en la uva: Vicuña, Vallenar. Por último, se radicó en Copiapó donde arrienda una pieza. A través de "una amistad" tomó contacto con un contratista que la colocó en labores "en seco" - amarra- y "en verde" -raleo- con contrato por un año, siguiendo con las faenas de la uva todo el año en Copiapó y valles del sur ya que está a merced del contrato anual logrado como "favor para tener papeles". Su horizonte es volver a Trujillo junto a los suyos por lo poco que gana en la uva (el salario mínimo), sometida al imperativo de la subcontratación, "porque el trabajo de casa (como empleada) es más tranquilo, rápido y descansado" y no la somete a ser testigo de peleas y agresiones contra peruanos que se dan en los potreros, aparte lo engorroso de los trámites para obtener visa.

Originaria de Lima, Milagros estudió para secretaria en contabilidad y administración de sistemas. Vive en San Felipe; hace tres años se vino con sus dos hermanos menores siguiendo a su madre separada, asesora del hogar, que migró de Lima dos años antes. Esta joven mientras obtenía la visa hizo comercio ambulante. Llegó a Copiapó por una amiga peruana que trabaja en una empresa frutícola trasnacional con filiales en San Felipe, Copiapó y otros lugares. En esta empresa buscaban gente para trabajar en Copiapó. Fue la primera vez que trabajó en la uva con contratista, de ahí se fue a Combarbalá y después a Rancagua a las mismas labores y empresa. Es jefa de línea en packing, tiene "uvas hasta abril y luego viene el limón y la mandarina". Su estrategia: "trabajar con la misma empresa contratista y mostrar mi trabajo", contribuir en su casa y ayudar a su madre en la educación de sus hermanos lo que se hace posible "por el hecho de ser soltera y no tener hijos ni compromiso" lo que le permite "salir" afirmando: "por eso que todavía no quiero formar una familia". 
Las tres jóvenes de Arica son amigas y viajaron a Copiapó donde alojaron en el Hogar de Cristo y se contactaron con la $\mathrm{OMIL}^{16}$ para lograr trabajo directo en una empresa donde les darían alojamiento en campamento. Algunas ya tenían experiencia con contratistas. Maricel, es hija de padres bolivianos y vive con ellos. Con educación media completa y con estudios en Alimentación y Dietética ha trabajado en hoteles, restaurantes, pesqueras, generalmente sin contrato pues a las jóvenes las emplean como "practicantes". Primera vez que sale a trabajar a las temporadas. Es "del pensamiento de que hombres y mujeres: parejito"..."He estado en cocina, alimentación, oficina, contabilidad como también he estado haciendo electricidad, se hacer radieres, igual que un hombre, construcción, de todo. Me gusta aventurarme en un montón de cosas". No obstante, señala que en Arica ese tipo de trabajo "lo tienen copado los hombres, peruanos y bolivianos y no contratan mujeres". Ha estudiado de todo: "electricidad, administración, contabilidad, revestimiento (flexit, cerámica, pasta muro, radier), primeros auxilios, cuidado de enfermos, repostería, comida china, comida internacional, comida sana, de todo pero igual terminas en la misma, en trabajos temporales". Paula tiene educación secundaria completa, segundo año que viene a Copiapó. Vive con su hermana mayor que tiene un hijo pequeño en Arica donde trabaja fileteando anchoas como sus compañeras de ruta. Ganaban cinco mil pesos diarios sin almuerzo mientras en la uva ganan más. Ha trabajado en zapatería, vendedora, cajera, haciendo inventarios en otra tienda, reponedora, venta de ropa americana, en bodega siempre sin contrato, en cambio, sostiene: "llegué aquí y me hicieron contrato altiro" para trabajar "en verde" y después en el packing. Judith, es chilena/aymara, $4^{\circ}$ medio en politécnico, vive con una tía (padres separados). Va "bajando" a lo largo del año de norte a sur. Trabajó en Arica, en un centro de llamados e industria pesquera; en Iquique, y hace cuatro años en packing de Copiapó. Después se va a Ovalle ya que en Arica, "en las pesqueras, en los filetes pagan mal, no alcanza para ahorrar" admitiendo que "cuando una no tiene una pareja se le hace más fácil ir viajando por diferentes lugares y conoce gente".Dado que una de ellas ya tenía experiencia en otros valles, las tres siguieron al sur para continuar con el trabajo de packing en la uva antes de retornar a Arica.

Las dos entrevistadas de Temuco, estudiantes universitarias en Educación Intercultural, son mapuche de comunidades indígenas. Ingresaron a una empresa a través de un contratista, luego se fueron a otra empresa donde no les pagaron más de $\$ 120.000$ por embalaje pero "como la fruta estaba mala" las trasladaban a otras faenas por \$ 6.000 al día las 8 horas. Ir a Copiapó a la uva tenía por motivación pagar la matrícula y deudas en la universidad. Frustrante por no lograr obtener el salario que pretendían, con esta experiencia piensan que la próxima temporada debieran lograr trabajo directo con las empresas pues, en estas condiciones, "se gana plata". Este año entienden que "pagamos el noviciado".

Proyectos de estudios y capacitación, versatilidad laboral, apoyo a los gastos y ahorro a sus familias, mantenimiento en soltería, casi todas con estudios secundarios completos y algunas con formación técnicoprofesional hasta universitaria, las jóvenes siguen las faenas de la uva no obstante no obtengan ingresos como las mayores pero logren mantenerlos varios meses al año ya que en otras ocupaciones y por los cambios de empleo que muestran sus trayectorias laborales, usualmente se las remunera como "practicantes" en el nivel o bajo el salario mínimo. Aventurarse en los viajes a la temporada, más allá de satisfacer necesidades monetarias y aumentar los ingresos que obtienen donde viven les procura experiencia y libertad, conocimiento del medio -empresas, contratistas, calidad de los campamentos- que les permiten de año en año elegir mejor donde trabajar.

\section{Especialización en las faenas de la uva: las jefas de hogar}

Las jefas de hogar migran al valle y desde el valle hacia otros valles del sur. Las mujeres con pareja e hijos no parecen migrar. Cuando se trata de jefas de hogar que deben atenerse sólo a sus ingresos para la reproducción económica de la familia, ellas buscan alargar el tiempo de salarización en la uva lo que pueden lograr desplazándose de valle en valle conforme va madurando la fruta. La hipótesis de que el motor de las migraciones se encuentra en los altos montos salariales que las mujeres pueden alcanzar en los meses de labores en packing a costa de la extensión de la jornada laboral es plausible. A partir del análisis de los ciclos migratorios caso a caso y de la inserción de las temporeras en distintos puestos de trabajo entre fines de la primavera y el verano y otoño -como supervisoras, limpiadoras, embaladoras- podemos colegir que son las posibilidades de lograr salarios más altos lo que las motiva a emplearse en las temporadas de la uva en distintos valles, logrando con ello extender el tiempo de salarización a varios meses. Son las que denominamos como "temporeras largas" que, a diferencia de los "temporeros largos", cambian de empresa y 
valle mientras ellos trabajan en la misma empresa con contratos fraccionados que duran once meses. Seguir las labores de packing debiera responder no sólo a su situación familiar sino también al proceso de calificación que logran algunas mujeres, tras años de experiencia en la limpia y embalaje de uva o, como supervisoras de línea. De hecho, al analizar las trayectorias laborales de las temporeras de Copiapó, de las de Vallenar, Vicuña, valle de Aconcagua que se mueven entre valles, todas ellas aunque trabajen en otras faenas como las de potrero "en verde", lo que las motiva a moverse de valle en valle es el packing. En los lugares de destino de la migración así como en los lugares de residencia, las plantaciones de parronales están extendidas. Ellas, desde jóvenes han aprendido a trabajar en la uva lo que les permite lograr altos rendimientos y mayores salarios por caja o tareas de vigilancia. A diferencia de estas mujeres con mayor movilidad laboral, las casadas aunque tengan este tipo de habilidades no migran y las más calificadas en labores donde se gana más prefieren trabajar en el valle en labores peor pagadas o cuyas condiciones de trabajo son más duras como la pasa y las aceitunas. Para las temporeras residentes en Copiapó que migran al sur una vez que han finalizado las labores de packing en el valle, la familiarización con las labores de la uva radica en que este valle está especializado en este cultivo como otros valles de Atacama, Coquimbo y Aconcagua. No trabajan en la cosecha de aceitunas pues los salarios son mucho más bajos; ni en las pasas pues es un "trabajo sucio" aunque bien pagado pero sin las ventajas del contrato de trabajo ni comida. Por el contrario estas jefas de hogar, migran a otros valles siguiendo las labores de packing sólo en la uva donde pueden ganar al mes entre \$400.000 a \$ 1.000 .000 según su rendimiento y puesto de trabajo. No es sólo la especialización en los puestos de trabajo y tareas mejor pagadas las que las impulsan a migrar, sino su situación familiar que les da libertad para salir y satisfacer las necesidades económicas que deben cubrir. Entre las jóvenes y adultas con hijos (25 a 52 años) se encontró a jefas de hogar que vivían en ciudades y pueblos, se desplazan entre las regiones de Valparaíso, Coquimbo y Atacama al interior del país y desde países andinos. Estos desplazamientos laborales se decodificaron de distinta manera: para algunas como "sacrificio" y culpa de dejar hijos solos o con sus abuelas o hijas mayores justificando la salarización y las migraciones "por falta de marido". Otras en cambio, se definen como jefas de hogar que suelen llevar a los hijos y parientes a los lugares donde migran o bien reposan en la parentela femenina para su cuidado como forma de vida internalizada con autonomía de figuras masculinas.

\section{Jefas de hogar que migran con contratistas}

De Vallenar (Atacama) y Vicuña (Coquimbo) trabajan casi el año completo en la uva tanto en faenas "en seco", "en verde" como en packing ya sea cerca de donde viven, o en otros valles al norte o sur. El motor de la migración es el empleo en los packing pues "se gana más" y tienen suficiente experiencia en el rubro como para alcanzar altos rendimientos. Están sometidas a la subcontratación y es este agente contratista el que favorece el traslado de valle en valle.

GRÁFICO $\mathbf{N}^{\circ} 2$

JEFAS DE HOGAR QUE MIGRAN CON CONTRATISTAS. OCUPACIONES Y LUGARES DE TRABAJO A LO LARGO DEL AÑO

\begin{tabular}{|c|c|c|c|c|c|c|c|c|c|c|c|c|}
\hline EDAD/ORIGEN & MAY & JUN & JUL & AGO & SEP & OCT & NOV & DIC & ENE & FEB & MAR & ABR \\
\hline \multicolumn{13}{|l|}{ Irene, 51 años } \\
\hline Vallenar, Chile & \multicolumn{6}{|c|}{ Faenas "en verde" Vicuña } & \multicolumn{3}{|c|}{ Packing Copiapó } & \multicolumn{3}{|c|}{ Packing Valles sur } \\
\hline \multicolumn{13}{|l|}{ Nena, 45 años } \\
\hline Vicuña, Chile & & \multicolumn{5}{|c|}{ Faenas "en verde" Vicuña } & \multicolumn{3}{|c|}{ Packing Copiapó } & \multicolumn{2}{|c|}{$\begin{array}{c}\text { Packing valles del } \\
\text { sur }\end{array}$} & \\
\hline \multicolumn{13}{|l|}{ Rosa, 45 años } \\
\hline Vicuña, Chile & & \multicolumn{5}{|c|}{ Faenas "en verde" Vicuña } & \multicolumn{3}{|c|}{ Packing Copiapó } & \multicolumn{3}{|c|}{ Packing valles del sur } \\
\hline
\end{tabular}

Madre y abuela, Irene trabaja en la uva "desde cuando empezó la parra en el valle de Copiapó, el año 1988. Acá (valle del Huasco) se plantó antes y vinieron a buscar gente acá porque sabían el trabajo. Yo tenía 22 años". A sus dos hijas pequeñas las dejaba al cuidado de su hermana al separarse de su marido temporero que nunca estaba en la casa. "Sirvió -agrega- para puro ponerle el apellido a las niñas". Su trayectoria laboral muestra el recorrido por varios valles hasta muy al sur, con contratistas. ¿Razones?: "cuando tienes marido puedes compartir la casa pero cuando estás sola debes buscar donde se gane más, tienes que ir al sur si se gana más o devolverte al norte". Hoy alterna trabajo con cuidado de su nieta mientras su hija se va a las 
temporadas en el valle del Huasco al interior de Vallenar. Se hace visible un reemplazo generacional para mantener la casa pero además una retribución a su hija puesto que "a los niños de uno los tuvo que dejar con otra persona entonces ahora se compensa". Fernanda, su hija trabaja el resto del año en una oficina, "colocando tarjetas de crédito y en primavera y verano en la uva a trato".

Nena, tiene dos hijas. Una y la nieta vive con ella; separada de su conviviente, padre de sus hijas, trabaja en las temporadas en Copiapó. A los 17 años empezó en la parra en el valle del Elqui, hasta ahora en el de Copiapó y otros valles. Comienza en junio con la amarra de la parra; luego se va a una empresa donde trabajó en potrero y packing, en este último con horario desde la 10 am. hasta las 4 de la mañana, "ahí gano, cuando se paga por racimo y como soy rápida, me hacía mis mone'as. Ahora estoy de seleccionadora de uva acá en Copiapó y ayer me hice $\$ 25.000$ pero me hago $\$ 12.000$ casi todos los días". Terminada la temporada se va con contratista a Vicuña y después a Rancagua. Hace su salario viajando ya que "uno en esta pega tiene que alejarse para ganar una miseria".

Rosa es madre de 4 hijos. Trabaja con contratistas, quienes "te quitan la mitad del sueldo.. Si reclamas por algo que es justo te dice que eres conflictiva y te apunta con el dedo, te quedas marcada y te vas por conflictiva. Ninguno podemos decir lo que realmente sentimos porque atrás están nuestras familias, mis hijos entonces no podemos perder el trabajo aunque esté harta, es la necesidad lo que prima". Según ella, perdió a su esposo "por salir a trabajar, por las ausencias en el hogar, muchas ausencias y eso genera separaciones, es el costo que pagas por tus hijos". En cuanto a sus desplazamientos, opina: "tienes que apechugar porque no tienes marido". Ello implica la extensión de la jornada laboral: "por ejemplo, mira, el otro día entramos en Rio Blanco a las 10 de la mañana y salimos al otro día a las 6 de la mañana. Nos fuimos cantando los pajaritos. Ni dormí, tomé desayuno, me fui a mi pieza a esperas la 1 para empezar de nuevo. A ellos no les conviene que trabajes cansada y lento entonces te dan una coca-cola, le echan no se qué para tenerte despierta. Con eso me sentía como nueva, todas las compañeras se sentían así y sacamos ligerito el montón de uva que había".

\section{Jefas de hogar que migran con su familia}

En otros casos, las jefas de hogar suelen migrar con miembros de su familia y red de parientes aunque también migren solas algunas temporadas.

Lidia es madre soltera de dos hijos de 17 y 12 años, es el único sostén económico estable de su familia y pasa buena parte del año en Ovalle y Copiapó en las labores de packing y "en verde" mientras el resto del año trabaja en el valle de Aconcagua donde vive. Al final del verano en un packing de Los Andes con lo cual tiene un salario casi todo el año. Su hija cursa $4^{\circ}$ medio y se hace cargo de la casa y vigila los estudios de su hermano menor mientras su madre está fuera. Tanto su hija como su madre (Olga) la acompañan en los veranos a Copiapó a trabajar en las faenas de la uva, su madre en el potrero y aseo de packing, su hija en el packing de anotadora.

\section{GRÁFICO $\mathbf{N}^{\circ} 3$}

JEFAS DE HOGAR Y GRUPOS DE PARENTESCO QUE MIGRAN CON SU FAMILIA. OCUPACIONES Y LUGARES DE TRABAJO A LO LARGO DEL AÑO

\begin{tabular}{|c|c|c|c|c|c|c|c|c|c|c|c|c|}
\hline EDAD/ORIGEN & MAY & JUN & JUL & AGO & SEP & OCT & NOV & DIC & ENE & FEB & MAR & $A B R$ \\
\hline \multicolumn{13}{|l|}{ Olga, 58 años } \\
\hline Los Andes, Chile & \multicolumn{5}{|c|}{ Labores de casa, vigilancia nietos Los Andes } & \multicolumn{3}{|c|}{ Faenas "en verde" Copiapó } & \multicolumn{4}{|c|}{$\begin{array}{c}\text { Labores de casa, vigilancia nietos Los } \\
\text { Andes }\end{array}$} \\
\hline \multicolumn{13}{|l|}{ Lidia, 35 años } \\
\hline Los Andes, Chile & $\begin{array}{c}\text { Venta } \\
\text { de fruta } \\
\end{array}$ & \multicolumn{5}{|c|}{ Faenas "en verde" en Ovalle y Copiapó } & \multicolumn{3}{|c|}{ Packing Copiapó } & \multicolumn{3}{|c|}{ Packing Los Andes } \\
\hline \multicolumn{13}{|l|}{ Claudia, 17 años } \\
\hline Los Andes, Chile & \multicolumn{6}{|c|}{ Estudios, cuidado de hermano } & \multicolumn{3}{|c|}{ Packing Copiapó } & \multicolumn{3}{|c|}{ Estudios } \\
\hline
\end{tabular}

De esta forma se constituyen los ingresos para dos hogares, el suyo y el de su madre viuda. Una amplia red inscrita en los lazos de parentesco hace de soporte a la ausencia de la madre gran parte del año. De hecho, 
4 de las hermanas de Lidia son temporeras; una de ellas, la que la inició las migraciones a Copiapó, actualmente casada y temporera en Los Andes, también vive cerca y es alguien a quién pueden recurrir sus hijos en su ausencia. Lidia recorre los valles del norte casi todo el año. Llevó a su hija mayor al campamento en Ovalle cuando cumplió nueve años. "Me la cuidaban mis compañeras; después a Copiapó me los llevé a los dos, uno busca una señora allá y le paga. Tú dices: tengo que ganar quince mil, cinco mil para la comida y el cuidado, porque no puede volver sin nada". Los hijos se van con ella en diciembre, cuando salen de la escuela, para volver en febrero a clases. Ha viajado a las parras con una hermana y su hermano menor aparte sus hijos y su madre. Se hace de salario casi todo el año en la uva, salvo a fines de otoño. "En mayo ya no hay trabajo en casi ningún lado, pero me las arreglo; compro naranjas y las vendo, ropa usada que vendo en la feria; en junio, julio, obligada me tengo que ir a Copiapó, a la poda, la amarra, la cosecha, después al packing". Para cubrir sus necesidades económicas tiene que ganar a lo menos $\$ 15.000$ diarios. "Cuando la fruta está buena, me los gano a las diez de la noche; cuando está mala, a las cuatro de la mañana".

Erika, hija de minero y madre dueña de casa, es separada de un minero. Tres hijos, la mayor separada con 2 niños, un estudiante en agronomía en una universidad de Iquique y el menor en el liceo en Copiapó. Desde que empezó a trabajar su madre la ayudó a criar a sus hijos; trabaja en la uva desde los 25 años por la dimisión de su marido de las responsabilidades económicas parentales con horarios muy largos, en particular en verano. Vive en Copiapó donde tiene su propia casa que arrienda allegándose recientemente al hogar de su hija y nietos parte del año ya que vive varios meses en Melipilla. Ambas trabajan en la uva. Desde hace 8 años una vez terminada la temporada en el valle en la primera quincena de febrero, viaja a Melipilla y trabaja en un packing en Rapel desde la segunda quincena de febrero hasta abril cuando termina la temporada de la uva. Gana bien entre mediados de diciembre y la primera quincena de abril desempeñándose como embaladora, supervisora o como contratista de fuerza de trabajo para una empresa de Rapel. El inicio de la migración al sur corresponde al momento en que sus hijos pueden valerse por si mismos bajo el cuidado de su abuela o de la hermana mayor. Comenzó como embaladora, luego como supervisora y jefa de línea aunque también trabaja "en verde" en el valle de Copiapó durante inviernos y primavera en el "cepillado" y "raleo" de uva. Hace cuatro años la buscaron para que trajera trabajadores de Copiapó a Rapel. Ella trae a una línea completa que se compone de 30 trabajadoras/es entre limpiadoras, embaladoras y paletizadores; a veces, trae hasta dos líneas que incluyen a hijos, parientes, compadres, vecinos y amistades. Arrienda dos casas en Melipilla donde aloja a los temporeros/as, otra para ella, sus hijos, nietos y cercanos.

\section{GRÁFICO N ${ }^{\circ} 4$}

JEFA DE HOGA QUE MIGRA CON SU FAMILIA. OCUPACIONES Y LUGARES DE TRABAJO A LO LARGO DEL AÑO

\begin{tabular}{|c|c|c|c|c|c|c|c|c|c|c|c|c|}
\hline EDAD/ORIGEN & MAY & JUN & JUL & AGO & SEP & OCT & NOV & DIC & ENE & FEB & MAR & ABR \\
\hline \multicolumn{13}{|l|}{ Erika, 52 años } \\
\hline Copiapó, Chile & \multicolumn{2}{|c|}{ Tejido } & \multicolumn{5}{|c|}{ Faenas "en verde" Copiapó } & \multicolumn{3}{|c|}{ Packing Copiapó } & \multicolumn{2}{|c|}{ Packing Rapel } \\
\hline Karina, 26 años & \multicolumn{7}{|c|}{ Cuidado de sus hijos Copiapó } & & & & & \\
\hline Juan, 22 años & \multicolumn{7}{|c|}{ Estudios universitarios Iquique } & & & & & \\
\hline Oscar, 14 años & \multicolumn{7}{|c|}{ Estudios secundarios Copiapó } & & & & & \\
\hline
\end{tabular}

La estrategia de migrar al sur y trasladar a toda la familia a las labores de packing radica en que todos los hijos logran ganar para sus gastos. Estas modalidades de combinar trabajo en Copiapó y Rapel varía de año en año, se ha ido con el hijo mayor, recientemente con los tres y a veces sola. En la última temporada se organizó con su hija para responder al trabajo en una empresa de Copiapó y viajar ella a Melipilla mientras Karina se quedó en Copiapó. Una forma de obtener ingresos fuera de la agricultura es el tejido de ropa de bebés lo que Erika hace a lo largo del año, por las noches pero sobre todo en invierno. Estos productos los entrega en diferentes tiendas en Copiapó y Antofagasta.

La relación trabajo-familia ha variado a lo largo de su trayectoria laboral. Las tareas de cuidado dados los horarios y lugares de trabajo han sido derivadas ya sea a su madre -cuando los hijos estaban chicos- ya sea a su hija mayor con quién mantiene hoy una relación de reciprocidad con el cuidado de sus nietos, cuando ella puede y su hija lo requiere.

Jefas de hogar que migran en grupo 
Otro caso incluye a dos temporeras ( 32 y 38 años) de Tierra Amarilla al interior de Copiapó, que viven juntas, trabajan en el valle y cuando la temporada termina se van al sur. Comparten tanto los gastos, el trabajo como los proyectos migratorios. Una de ellas tiene dos hijos que quedan al cuidado de su madre cuando termina la temporada de la uva el mes de febrero en Copiapó y se van al sur y, a lo largo del año sobre todo sabiendo que las jornadas laborales son muy largas sobre todo en verano. "Siempre los he dejado con ella, cuando me voy al sur y en lo que es el tiempo de packing, noviembre, diciembre, enero acá". Desde mediados de febrero hasta fines de marzo, comienzos de abril, se van a San Fernando con un grupo de temporeros/as, amistades que se han hecho en el trabajo o en la población que habitan. Esto les permite negociar mejores salarios; viajando varios pueden lograr una mejor inserción en las empresas porque se hacen cargo de faenas completas en los momentos en que las empresas deben cosechar la uva y embalarla.

GRÁFICO N 5

JEFAS DE HOGAR QUE MIGRAN EN GRUPO. OCUPACIONES Y LUGARES DE TRABAJO A LO LARGO DEL AÑO

\begin{tabular}{|c|c|c|c|c|c|c|c|c|c|c|c|c|}
\hline EDAD/ORIGEN & MAY & JUN & JUL & AGO & SEP & OCT & NOV & DIC & ENE & FEB & MAR & ABR \\
\hline \multicolumn{13}{|l|}{ Ingrid, 38 años } \\
\hline Tierra Amarilla, Chile & \multicolumn{2}{|c|}{$\begin{array}{c}\text { Cosecha aceituna } \\
\text { Copiapó }\end{array}$} & \multicolumn{5}{|c|}{ Faenas "en verde" Tierra Amarilla } & \multicolumn{3}{|c|}{ Packing Tierra Amarilla } & \multicolumn{2}{|c|}{$\begin{array}{c}\text { Packing San } \\
\text { Fernando }\end{array}$} \\
\hline \multicolumn{13}{|l|}{ Edith, 32 años } \\
\hline Tierra Amarilla, Chile & \multicolumn{2}{|c|}{$\begin{array}{c}\text { Cosecha aceituna } \\
\text { Copiapó }\end{array}$} & \multicolumn{5}{|c|}{ Faenas "en verde" Tierra Amarilla } & \multicolumn{3}{|c|}{ Packing Tierra Amarilla } & \multicolumn{2}{|c|}{$\begin{array}{l}\text { Packing San } \\
\text { Fernando }\end{array}$} \\
\hline
\end{tabular}

En Copiapó trabajan en la uva, en potrero y packing intercalando con la cosecha de aceituna volviendo a trabajar en parking en el sur. El viaje al sur desde mediados de febrero hasta comienzos de abril supone preparación: "un mes antes de irnos al sur ya estamos hablando del sur. Coordinamos quién va a llamar a las oficinas del sur. Los números de los teléfonos los tenemos todos los que vamos a viajar entonces nos llamamos por teléfono y llamamos a las empresas donde vamos a llegar. Preguntamos cómo van a estar los precios, cuánto van a pagar a la embaladora, a la seleccionadora, si se necesita mozos, todo eso cosa que si vas en grupo ninguno quede nadando. Las que llevamos gente al sur somos nosotras porque nosotras empezamos a ir solas. Ganamos un millón de pesos cada una en el mes y entonces como estaba tan bueno llegamos contando y las niñas dijeron al otro año vamos y ahí nos fuimos doce para el sur". Sin embargo ese nivel de salario implica trabajar diez y ocho o diez y nueve horas seguidas "con un tiempo para el almuerzo de cuarenta minutos y para la colación de media hora". Y es por eso que ellas que son de "afuera" hacen paros involucrando a las trabajadoras locales de las empresas. "Le dije al jefe de packing que las embaladoras estábamos cansadas y que nos íbamos a parar. Se enojó y fue a la línea a retarnos a todas, casi nos echaron pero paramos. Si ya habíamos hecho las horas suficientes y si no, nos íbamos. Estuvimos tres horas paradas con la gente de la empresa, y nos subieron el precio".

\section{Jefa de hogar que trae a su familia a la temporada}

Fanny, peruana, madre soltera, dejó a su hijo con la abuela en Tacna para irse a trabajar primero a Arica y luego a Copiapó a las parras para mantenerse y enviar remesas para los gastos de su hijo. Vive en Copiapó hace dos años con una pareja de su misma edad, trabaja en la uva en el valle y viaja al sur siguiendo las labores de la uva. Su compañero, en la construcción, a veces, en la uva. Ella viaja a menudo a ver a su hijo a Tacna o bien, sus padres ${ }^{17}$ se desplazan a trabajar en la uva al valle junto a un hermano, ocasión para ver a su hijo. Arriendan una pieza a un peruano que arrienda a varios peruanos. La trayectoria migratoria de la joven comenzó a los 18 años de Tacna a Arica. El terminal de transporte fue el lugar de su primer enganche para trabajar en el ajo y la cebolla en el valle de Lluta a lo que siguió el trabajo en una panadería y luego empleo doméstico lo que duró cinco años con viajes intermitentes a Tacna. Aunque migró sola, su padre y un hermano ya trabajaban en la construcción en Arica desde donde, animados por Fanny, se desplazan a la temporada de la uva ${ }^{18}$. Su pareja hace 8 años que trabaja en Chile; se vino con su hermano que trabajaba como asalariado agrícola en el valle de Azapa. Estando en Arica, decidieron irse a Copiapó ya que una amiga peruana les dijo que "allá en Copiapó se ganaba plata" (...) "Yo vine porque a mi me dijeron de la uva, que era bueno y vine a probar; una amiga que ya estaba acá me llamó por teléfono y me dijo que nos viniéramos para acá. Nos vinimos y después nos llevaron a la uva; a mi me gustó, yo me quedé y después me fui para el 
sur, después volví para acá y después me fui para Perú otra vez cuando terminó la temporada, después me vine, me arrendé una pieza y nos quedamos aquí. Llevamos como dos años y medio". Los vínculos entre peruanos para los contactos laborales parecen ser importantes ya que implican apoyo para la llegada y acogida en el nuevo lugar. Se trata de desplazamientos "guiados" por relaciones de amistad y nacionalidad. "Mi amiga nos esperó, fui al terminal y nos dijo 'toma el colectivo y llega a tal lugar y yo les voy a estar esperando ahí'. Nos esperó y llegamos y ahí nos quedamos con ella en su pieza. Dormimos todos juntos y después arrendamos otra pieza de la misma casa".

\section{GRÁFICO N 6}

JEFA DE HOGAR QUE TRAE A SU FAMILIA A LA TEMPORADA. OCUPACIONES Y LUGARES DE TRABAJO A LO LARGO DEL AÑO

\begin{tabular}{|c|c|c|c|c|c|c|c|c|c|c|c|c|}
\hline EDAD/ORIGEN & MAY & JUN & JUL & AGO & SEP & OCT & NOV & DIC & ENE & FEB & MAR & ABR \\
\hline \multicolumn{13}{|l|}{ Fanny, 25 años } \\
\hline Tacna, Perú & \multicolumn{2}{|c|}{$\begin{array}{c}\text { Cosecha aceituna } \\
\text { Copiapó }\end{array}$} & $\begin{array}{c}\text { Habas } \\
\text { Copiapó }\end{array}$ & \multicolumn{4}{|c|}{$\begin{array}{c}\text { Faenas "en verde" Copiapó, } \\
\text { construcción comida a los } \\
\text { trabajadores }\end{array}$} & \multicolumn{3}{|c|}{ Packing Copiapó } & \multicolumn{2}{|c|}{ Packing Rancagua } \\
\hline
\end{tabular}

Nota: se consigna sólo su itinerario migratorio ya que sus parientes tienen hogar aparte

Ella alterna la temporada en el valle de Copiapó con viajes al sur por medio de un contratista, más aún, el contratista es necesario porque al comienzo "no teníamos papeles". Llega hasta Rancagua, San Fernando, donde "hacía dos turnos, como estaba allá iba a aprovechar. Trabajaba en la mañana cosechando hasta medio día y después entraba al packing hasta la noche. Me maté trabajando un mes y medio pero gané bien y me fui contenta". Empieza en la uva en primavera hasta el verano, sigue con las aceitunas (mayo-junio) y después con las habas y a fines de temporada con las pasas. Trabaja todo el año, en Julio en la poda y amarra de parras. Lo hace con contratista "pues las empresas no reciben peruanos en forma directa" mientras que con los contratistas trabajan en varias empresas y distintas labores lo que le permitió irse al sur el pasado año entre febrero y abril. En tiempos muertos lava ropa y hace aseo de departamentos o ayuda a su pareja en la construcción donde se le encarga la comida para los trabajadores. En la parra logra un ingreso mensual cercano a los \$300.000 y más, a veces viviendo en campamentos donde "ahorra" lo que gasta normalmente en la pieza que arrienda (gas, alimentación).

\section{Migrantes hombres: entre la construcción, la parcela y las parras}

Para establecer comparaciones con las migrantes mujeres, incluimos a algunos de los migrantes hombres. Entre ellos, se encontró a jefes de hogar con hijos, con pareja y separados y a solteros sin hijos, chilenos, peruanos, ecuatorianos e indígenas chilenos. Los migrantes estaban motivados por obtener ingresos en las labores de la uva que superan los ingresos locales con montos cercanos al salario mínimo y períodos de desempleo. La migración para trabajar en la temporada de la uva implicaba a lo menos duplicar los ingresos locales. Esto se logra mediante la realización de las labores de poda, raleo y cosecha. Los ingresos salariales están dirigidos a mantener a sus familias, mantenerse ellos mismos si son solos o como sostén monetario para mantener economías campesinas cuando son pequeños propietarios. Se encontró a personas con estudios técnicos (migrantes de países andinos), obreros de la construcción (chilenos y peruanos), a campesinos mapuche propietarios de tierras y a hombres que hacen distintos oficios, entre ellos chilenos, mapuche, ecuatorianos y peruanos. Entre los temporeros migrantes con familia ya sea chilenos o peruanos se observa que la migración reiterada por varios años y la ausencia del hogar durante a lo menos seis meses al año que es lo que dura el trabajo de poda, raleo y cosecha es un importante factor de desarticulación familiar y de separaciones conyugales. En los casos de los peruanos, la migración reviste más tiempo puesto que tienden a instalarse en lugares donde hay empleo y salarios convenientes que les permitan vivir a ellos y enviar remesas a sus familias. Independientemente que se desplacen para prolongar el tiempo de salarización y que viajen a su lugar de origen, las migraciones que concluyen en el cambio de lugar de residencia contribuyen a la separación conyugal. Suele ocurrir que ellos funden una nueva pareja en el lugar donde se instalan y que preserven los lazos familiares a través de las remesas en dinero a sus hijos. 


\section{GRÁFICO $\mathbf{N}^{\circ} 7$}

TEMPOREROS HOMBRES. OCUPACIONES Y LUGARES DE TRABAJO A LO LARGO DEL AÑO

\begin{tabular}{|c|c|c|c|c|c|c|c|c|c|c|}
\hline \multirow{2}{*}{ EDAD/ORIGEN } & \multicolumn{10}{|c|}{ Patrón migratorio y ocupacional masculino } \\
\hline & MAY & JUL & AGO & SEP & OCT & NOV & DIC & ENE & MAR & ABR \\
\hline \multirow{2}{*}{$\begin{array}{c}\text { Campesino mapuche } \\
\text { Araucanía }\end{array}$} & \multirow{2}{*}{\multicolumn{4}{|c|}{ Actividades productivas tierra propia }} & & & & & & \\
\hline & & & & & \multicolumn{4}{|c|}{ Faenas de raleo y cosecha Copiapó } & \multicolumn{2}{|c|}{$\begin{array}{c}\text { Faenas de raleo y cosecha } \\
\text { valles del sur }\end{array}$} \\
\hline \multirow{2}{*}{$\begin{array}{l}\text { Migrante peruano } \\
\text { Copiapó }\end{array}$} & & & & & & & & & & \\
\hline & \multicolumn{4}{|c|}{ Obrero construcción Copiapó } & \multicolumn{4}{|c|}{ Faenas de raleo y cosecha Copiapó } & \multicolumn{2}{|c|}{ Construcción Copiapó } \\
\hline \multicolumn{11}{|l|}{ Migrante peruano } \\
\hline $\begin{array}{c}\text { Tacna - Arica - } \\
\text { Copiapó }\end{array}$ & \multicolumn{4}{|c|}{ Albañil construcción Arica } & \multicolumn{4}{|c|}{ Faenas de raleo y cosecha Copiapó } & \multicolumn{2}{|c|}{ Construcción Arica } \\
\hline \multirow{2}{*}{$\begin{array}{c}\text { Obrero mapuche } \\
\text { Araucanía }\end{array}$} & & & & & & & & & & \\
\hline & \multicolumn{4}{|c|}{ Obrero construcción Temuco } & \multicolumn{4}{|c|}{ Faenas de raleo y cosecha Copiapó } & \multicolumn{2}{|c|}{$\begin{array}{c}\text { Faenas de raleo y cosecha } \\
\text { valles del sur }\end{array}$} \\
\hline \multirow{2}{*}{$\begin{array}{l}\text { Migrante peruano } \\
\text { Copiapó }\end{array}$} & & & & & & & & & & \\
\hline & \multicolumn{4}{|c|}{ Obrero construcción Copiapó } & \multicolumn{4}{|c|}{ Faenas de raleo y cosecha Copiapó } & \multicolumn{2}{|c|}{$\begin{array}{c}\text { Faenas de raleo y cosecha } \\
\text { valles del sur }\end{array}$} \\
\hline \multirow{2}{*}{$\begin{array}{c}\text { Obrero no calificado } \\
\text { San Felipe }\end{array}$} & & & & & & & & & & \\
\hline & \multicolumn{4}{|c|}{ Oficios varios } & \multicolumn{4}{|c|}{ Faenas de raleo y cosecha Copiapó } & \multicolumn{2}{|c|}{$\begin{array}{c}\text { Faenas de raleo y cosecha } \\
\text { valles del sur }\end{array}$} \\
\hline
\end{tabular}

Dos elementos inhibían la desarticulación de la familia: la tierra (campesino mapuche) y la educación de los hijos en la universidad (peruano albañil). Irse desde la Araucanía a la uva para juntar dinero y comprar ganado, hacer mejoras a la parcela, construir un galpón, figuran, entre las razones que impulsan a un campesino mapuche a migrar a Copiapó y trabajar en otros valles hasta que finaliza la temporada ${ }^{19}$. En el caso del albañil (padre de Fanny) peruano que tiene a su familia en Tacna, él y su hijo mayor migraron a Arica donde ambos viven y trabajan en la construcción. En la temporada de la uva viajan a Copiapó impulsados por la hija que se ha radicado en Copiapó para trabajar como temporera en ese valle y otros valles.

\section{Conclusiones}

El carácter temporal del empleo deslocaliza a los trabajadores/as de su lugar de residencia no sólo cotidianamente por las largas jornadas laborales, sino además por las migraciones para prolongar el tiempo de salarización ya que "hay que hacerse el salario viajando de valle en valle" o trasladarse de país "porque en Chile hay más trabajo y se gana más". Se definen como "trabajadores del clima", pues siguen en latitud la maduración de la uva. Entre ellos se sostiene: "el trabajo no viene a nosotros, nosotros andamos detrás del trabajo". La vida de campamento que llevan los inmigrantes al valle lejos del hogar es un factor de alargamiento de la jornada laboral y de ahorro en gastos de manutención (Valdés, 2010).

Las condiciones laborales, las largas jornadas diarias que se producen por los regímenes salariales "a trato" y las migraciones estacionales para acceder a estos empleos que a veces culminan con la radicación de trabajadores en Copiapó como en el caso de los peruanos de ambos sexos, es un importante factor de remodelamiento de la familia conyugal que en la mayoría de los entrevistados de ambos sexos caracterizó a la generación mayor, vale decir, a los padres de estos trabajadores.

Varias consecuencias tiene en la familia el distanciamiento de algún miembro al insertarse en forma temporal las faenas de la uva. En primer lugar, desarticulación de la familia de manera temporal o permanente causada por la deslocalización del lugar de trabajo con respecto al lugar de residencia, y la ausencia temporal o permanente del padre y pareja masculina o temporal de la madre sin pareja. Las mujeres migran cuando tienen hijos a cargo y no tienen pareja; ellas no sólo juegan el papel de proveedoras de sus familias sino suelen trasladar a sus familias al lugar de trabajo, cuando los adolescentes pueden trabajar o cuando no tienen con quién dejarlos siendo pequeños. Cuando los hijos son pequeños derivan su cuidado a la red femenina de parentesco: a sus propias madres, hijas mayores, hermanas a diferencia de las residentes que suelen contar 
con sistemas públicos de cuidado infantil. En cambio los hombres migrantes se separan de sus familias de manera estacional o permanente preservando su papel de proveedores a través de las remesas en dinero en el esquema del patrón de familia con división de esferas donde a ellos les cabe la provisión económica y a sus parejas el cuidado de los hijos (salvo en un caso de mapuche migrante con pareja empleada doméstica en Santiago que mandaban cuidar a la hija en una mujer de la comunidad indígena de origen). En el caso de los temporeros hombres, la raíz de las migraciones reside en la falta de trabajo -o de tierra-, a los bajos salarios que ganan en sus lugares de residencia y las posibilidades que brinda el salario obtenido en la temporada para mejorar y hacer producir la tierra, cuando la hay. En el caso de las mujeres con hijos, la raíz de la salarización y de las migraciones radica en la "falta de marido" que enuncian algunas de las que se han separado, justamente por su inclusión en el mercado de trabajo y la ausencia del hogar. En el imaginario de estas mujeres se preserva el patrón de familia conyugal, rota, fracturada, a causa del trabajo. En cambio, las más jóvenes junto a las trabajadoras mejor calificadas, especializadas en la uva, no apelan a no tener marido sino a la necesidad de lograr ingresos para mantener a sus hijos ya que los padres son renuentes a asumir las responsabilidades parentales. Ellas pueden ganar más en los packing, duplicar hasta quintuplicar el salario mínimo a costa de traslados y del alargamiento de la jornada laboral. Seguir el empleo tiende entonces a desterritorializar a la familia.

Para hombres y mujeres, los salarios en la uva son superiores a los que se pagan en otras actividades aunque ciertas labores son pagadas en el nivel del salario mínimo, en particular entre los/as temporeros/as novatos, sin experiencia. Los temporeros suelen trabajar en la construcción cuando no hay empleo en la uva, en "pololos" en otras actividades, salvo un caso de campesino mapuche migrante; las mujeres en la aceituna, las hortalizas, los servicios (doméstico, cocina) no obstante las más experimentadas solo trabajen en la uva. Entre los hombres que trabajan más en potrero, las jornadas laborales son más cortas que entre las mujeres que trabajan parte del año en packing donde alcanzan montos salariales altos, desde $\$ 400.000$ a hasta un millón de pesos cuando son diestras, rápidas embaladoras o seleccionadoras y con jornadas laborales continuas cercanas a las diez y ocho horas de trabajo.

Los hombres siguen siendo los proveedores de la familia, con deberes familiares de sostenimiento económico lo que se encarna en las remesas en dinero; ahora lo son desde fuera, de viaje, bajo una forma de vida itinerante para proveerse de salario y con el malestar de enfrentar, en la mayoría de los casos, rupturas familiares. Ellos se desplazan de valle en valle trabajando normalmente en torno a las ocho horas de trabajo obteniendo por ello salarios que superan el salario mínimo. Es lo que fundamenta la migración, ganar más que donde viven, ya sea en Chile o Perú. Cuando nos centramos en los argumentos femeninos para explicar las migraciones, los padres de sus hijos están ausentes, se han ido y "no teniendo marido" hay que salir a trabajar a otros valles.

Las jefas de hogar, como consecuencia de las migraciones y horarios de trabajo, deben mantener a sus familias reposando normalmente en la red de parentesco femenina para el cuidado de los hijos y, a veces, llevándolos a los lugares de trabajo, o trayéndolos de vacaciones a Chile como en el caso de la joven peruana. En cambio los hombres no varían sus formas de vida habituales en cuanto tareas domésticas y cuidado de hijos pues sólo trabajan ya que son las madres de sus hijos las que se encargan de la crianza y el cuidado aunque las migraciones suelan ser la causa de la desarticulación familiar sin restarles el papel de coproveedores del hogar que, según las mujeres, no siempre cumplen.

Estas formas familiares han surgido como consecuencia de la desincronización temporal y espacial entre trabajo y familia, de la separación de estas dos esferas de la vida gatilladas por los regímenes de trabajo en la economía exportadora. Podemos hipotetizar entonces, que la economía de exportación desarticula a la familia moderno-industrial surgida de los regímenes fordistas en el período de industrialización; y que, en consecuencia, la flexibilidad laboral, acompañada por regímenes excepcionales de trabajo en una economía globalizada, constituye uno de los factores de transformación de la familia. Ello, en un contexto de desregulaciones laborales y de fragilización de los sistemas de protección social, lo que conduce a modelar nuevas formas de familia que dejan atrás los patrones de conyugalidad, paternidad y maternidad de la sociedad salarial. Lo que queda de manifiesto es que la familia es producto de la sociedad que habita, bajo nuevos patrones de reproducción de la sociedad, la cual enfrenta la paradoja de la individualización, pero que debe afirmarse en el parentesco, sobre todo en el caso de las mujeres jefas de hogar migrantes. Siguiendo a Lesnard (2009), esto es el resultado de los constreñimientos que genera la nueva organización del trabajo en 
el empleo del tiempo. Lo que se pone de relieve con esta forma de articulación entre trabajo y familia en presencia de migraciones estacionales, es un sistema de protección social enraizado en el parentesco y en las redes femeninas de apoyo que, al decir de Souza dos Santos puede definirse como "sociedad-providencia" (de bienestar) por la "movilización de la familia y de las redes de interconocimiento y de ayuda mutua....para el desempeño de funciones de seguridad social hasta ahora desempeñadas por el Estado" (Souza dos Santos, 1998:310). .

Esta "sociedad-providencia" se hace más visible aún al constatar que el fenómeno migratorio deja al desamparo a la familia que, dados los patrones de género de la sociedad contemporánea recae en las mujeres y en ausencia de la madre es la parentela femenina la que la suple en el hogar. Parte de la metamorfosis de lo social cuando las personas se sitúan a medio camino entre la inclusión y la exclusión social, como diría Castel (1995) es entonces la desarticulación familiar con la aparición de nuevas formas y arreglos de vida en común centrados en los referentes familiares y del parentesco a objeto de cubrir la desterritorialización de la familia.

\section{Notas}

\footnotetext{
${ }^{1}$ Investigadora responsable de Proyecto FONDECYT 1905007 en curso.
}

${ }^{2}$ El sector exportador generó el año 2007 el 7,5\% del empleo directo asalariado del país con un promedio de salario mensual de $\$ 434.566$, monto superior al promedio del resto de los asalariados. Los salarios promedio más elevados correspondieron a la minería (\$1.547.351), transporte y servicios (\$664.731) con los promedios inferiores en las empresas exportadoras agrícolas y pesqueras $(\$ 140.671)^{2}$, con montos cercanos al salario mínimo legal. Corregido, considerando trabajo de manera constante, este monto salarial asciende a \$264.386 (DIRECOM 2009: 4).

${ }^{3}$ Según la Encuesta CASEN, los temporeros de la fruta el año 2006 en un 64,4\% eran hombres y el 35,6\% mujeres. En la CASEN 2009 esta proporción varió del $66 \%$ en hombres y $34 \%$ mujeres debido a que se precarizó el empleo masculino. En números absolutos, los temporeros hombres aumentaron de 151.035 el 2006 a 165.238 el 2009, las temporeras aumentaron de 83.588 el 2006 y 84.998 el 2009 .

${ }^{4}$. Según la CASEN 2006 los temporeros hombres en un 46,2\% eran de origen urbano (53,8\% rural) mientras las mujeres temporeras eran en un 60,1\% urbanas (39,9\% rurales). La CASEN 2009 muestra un leve aumento proporcional de poblaciones urbanas masculinas en el empleo temporal: $48,3 \%$ de hombres y disminución relativa de las temporeras urbanas $(56,5 \%)$.

${ }^{5}$ No hay información sobre empleo agrícola. Se afirma que la mayoría de las migrantes peruanas se emplean en el servicio doméstico (Stefoni, 2002: 118)..

${ }^{6}$ Los temporeros/as indígenas correspondieron el año 2006 al 5,7\% del total de los asalariados temporales en la fruta; el 2009 al 6,4\% (CASEN).

${ }^{7}$ Al considerar los datos de los últimos Censos Agrícolas y de la Encuesta CASEN hay una importante disminución de los trabajadores agrícolas estables y el aumento de los temporales. En las dos últimas CASEN estos disminuyeron de 100.843 a 82.948 mientras los hombres temporeros aumentaron de 151.035 a 165.238 en el trienio 2006-2009.

${ }^{8}$ La participación laboral de las mujeres fue escasa bajo la sociedad salarial (20\%) y sólo aumentó con la globalización de las economías y los procesos de desregulación y reorganización del trabajo echando por tierra el modelo del hombre proveedor de la familia que acompaño un orden de género amparado por el Estado de Bienestar y su sistema de protecciones sociales.

${ }^{9}$ En este análisis se excluyeron entrevistas realizadas a temporeras de Ovalle migrantes a las temporadas de la uva de Vallenar, valle del Huasco.

${ }^{10}$ El número de huertos frutales en la región llega a 502 de los cuales 129 en el valle de Copiapó y 373 en el Huasco. En Copiapó las explotaciones se concentran en las de gran tamaño mientras en Huaco en la mediana y pequeña explotación. Catastro Frutícola de la III Región, CIREN-CORFO, Santiago 2005.

${ }^{11}$ Con respecto de la jefatura de hogar femenina a nivel de los hogares, entre los asalariados agrícolas un 19\% correspondió el año 2006 a mujeres lo que aumentó al 2009 al 22,8\%. En cambio, al analizar la proporción de mujeres jefas de núcleo en el total de asalariadas mujeres de la agricultura está aumento entre el año 2006 al 2009 del 35,6\% al 36,6\% el 2009.

${ }^{12}$ CIREN. Catastro frutícola de Atacama.

${ }^{13}$ Dentro de los entrevistados de ambos sexos testigo de migraciones definitivas se encontró dos situaciones. 1. Chilenas de la zona central que migraron al valle hace 10 a 3 años y se instalaron en la localidad de Los Loros; ahí fundaron pareja trayéndose también a otros familiares de su lugar de origen a vivir a esta localidad. Ellas trabajan como temporeras "en verde" y packing y sus parejas como mineros u obreros agrícolas. Esta localidad es testigo de radicaciones de poblaciones originarias del sur del país apostadas más allá de los límites antiguos de este pueblo. 2. Los migrantes de los países andinos en cambio residían en Copiapó y habían llegado a esa ciudad a 
través de redes con compatriotas. La residencia y la forma de albergarse generalmente está dada por redes entre peruanos y extranjeros. Suelen vivir en piezas arrendadas a otros peruanos en las poblaciones de la parte alta de Copiapó.

${ }^{14}$ El crecimiento de la ciudad de Copiapó en las últimas dos décadas, de localidades como Tierra Amarilla y Los Loros hacia el interior del valle, son reveladores de la radicación de migrantes originarios del sur del país y de países andinos. Censos de Población y Vivienda 1992 y 2002, INE, Santiago.

${ }^{15}$ Por temporero/a largo/a se entiende las situaciones laborales caracterizadas por el empleo en faenas estacionales a lo largo de casi todo el año con contratos sucesivos en una o varias empresas, en uno o distintos valles. "Diagnóstico en materia de salud ocupacional de trabajadores agrícolas de temporada en la Comuna de Coltauco", CEDEM, 2009. A diferencia de lo encontrado en este estudio para definir la situación laboral de los hombres, el caso de las migraciones a/y desde Copiapó da cuenta de la existencia de la "temporera larga" que supone traslado geográfico.

${ }^{16}$ Oficina de Colocación Municipal.

${ }^{17}$ Había 620 peruanos en esta ciudad el año 2009. Los padres de estos jóvenes peruanos son campesinos de Puno: los de ella migraron a Tacna por las malas cosechas mientras los de él permanecen en su tierra.

${ }^{18}$ Su padre (45 años, albañil) y hermano que se dedican a la construcción en Arica desde 1995, vienen a Copiapó hace 2 años a la temporada de la uva. El padre que tiene dos parcelas en Puno lo que le da producto una vez al año (papas, habas. ajos), señala: "por el estudio de mis hijos yo he salido de viaje". Su madre (45 años, comerciante) también se incorpora a trabajar en la uva cuando lleva a su nieto a Copiapó. En Tacna vende comida y está a cargo del nieto ( 9 años) y los dos hijos que estudian en la universidad.

${ }^{19}$ Constatamos en terreno en octubre 2010 y enero 2011 que en comunidades mapuche y huilliche de la Araucanía y Los Lagos, lo habitual de las migraciones estacionales al valle central y zona norte. Hombres y jóvenes de ambos sexos se desplazaran a trabajar en la fruta. Lo hacían en grupos de parientes. Como se dijo en nota más atrás, los indígenas que trabajan en la fruta aumentaron según la CASEN del 5,7\% del total de los temporeros al 6,4\% entre el 2006 y 2009.

\section{Bibliografía}

Abdelmalek, S. (2006), L'inmigration ou les paradoxes de l'alterité. Editions Raisons d'Agir, Paris.

Aldelhafid, H. (2007), Les récompositions culturelles. Sociologie des dynamiques sociales en situation migratoire. Presses Universitaires de Strasbourg, Francia.

Angeloff, Ph., T., Alonso y Maruani, M (2005), "Travail, famille et genre: une relation à double sens". En : Femmes, genre et sociétés. L'état des savoirs (M. Maruani edit.). La Découverte, Paris. pp.372-380.

Beck, U. (1998), La sociedad del riesgo. Paidós, Buenos Aires.

Canales, A. (2006), Panorama actual de las migraciones en América latina. Universidad de Guadalajara, Asociación Latinoamericana de Población, México.

Caro, P. y De La Cruz, C. (2009), Contratistas e intermediación laboral en la agricultura de exportación. CEDEM, Santiago.

CIREN/CORFO (2005), Catastro Frutícola la III Región, Santiago.

Comaille J. y C. Martin (1998), Les enjeux politiques de la famille. Bayard, París.

Castel, R. (1995), La metamorfosis de la cuestión social. Paidos, Barcelona.

Castel, R. (2009), La montée des incertitudes : Travail, Protections, Status de l'individu. Seuil, Paris.

De Souza Santos, B. (1998), De la mano de Alicia. Lo social y lo político en la postmodernidad. Ediciones Uniandes, Bogotá.

DIRECOM (2009), Empleo y salarios en el sector exportador. Departamento de Estudios, Santiago.

Díaz, Alvaro (1991), "Nuevas tendencias en la estructura social chilena. Asalarización informal y pobreza en los ochenta". En: Revista Proposiciones No 20, Santiago. Págs. 88-119.

Falabella, G. (1970), "Desarrollo del capitalismo y formación de clase: el torrante en la huella". En Revista Mexicana de Sociología. Vol XXXII, Nº1, 1970. 
Goody, J. (2002), La familia europea. Ed. Gráfica, Barcelona.

Kay, C. (2009), Estudios rurales en América Latina en el período de la globalización neoliberal ¿una nueva ruralidad? En Revista Mexicana de Sociología, Vol. 71, Num. 4, octubre-diciembre, 2009, pp. 607-645.

Lara, S.M. (2010), "Movilidad y migración de familias jornaleras: Una mirada a través de genealogías". En Revista de Metodología de Ciencias Sociales EMPIRIA, UNED. № 19, enero-junio, 2010. pp. 183-201.

Lesnard, L. (2009), La famille désarticulée. Les nouvelles contraintes de l'emploi du temps. PUF, Paris.

Maruani, M. (2000), "De la sociología del trabajo a la Sociología del empleo" en Revista Política y Sociedad No 34. Madrid. Págs. 9-17.

MIDEPLAN (2006 y 2009), Encuesta CASEN, Santiago.

Roudinesco, E. (2003), La familia en desorden. FCE, México.

Roussel, L. (1989), La famille incertaine. Odile Jacob, Paris.

Salazar, Gabriel (1986), Labradores, peones y proletarios. Ediciones SUR, Santiago.

Santana, R. (1980), Paysans dominés, CNRS, Paris.

Sassen, S. (2003), Contrageografías de la globalización. Género y ciudadanía en los circuitos transfronterizos. Traficantes de sueños, Madrid.

Ídem (2010), Territorio, autoridad y derechos. De los ensamblajes medioevales a los ensamblajes globales. Katz Editores, Buenos Aires.

Sennet, R. (2000), La travail sans qualités. Les conséquences humaines de la flexibilité. Albin Michel, Paris.

Stefoni, C. (2002), "Mujeres inmigrantes peruanas en Chile", en Papeles de Población, julio-septiembre, número 33, Universidad Autónoma del Estado de México, Toluca, México, pp. 118-145.

Théry, I. (1998), Couple, Filiation et Parenté aujourd'hui. Le droit face aux mutations de la famille et de la vie privée. Odile Jacob, Paris.

Ídem (2002), "Penser la filiation en Familles Permanence et métamorphoses". En : Familles. PUF, Editions des Sciences Humaines, Paris. Pp. 211-222.

Ídem (2005), "Dynamique de l'égalité de sexe et transformation de la parenté". En : Femmes, genre et sociétés. L'état des savoirs. La Découverte, Paris. pp. 159-166.

Valdes, X y Godoy, C. G (2005), Empleo y condiciones de trabajo en la producción de uva de exportación en el valle de Copiapó. CEDEM/Dirección del Trabajo. Informe investigación. Santiago.

Valdés, X (2010), “De cómo la economía de exportación y los regímenes excepcionales de trabajo construyen el espacio familiar”. En: Revista Proposiciones No 37, Pensar la Ciudad, Ediciones SUR, Santiago. págs. 115-123.

Ídem (2007), La vida en común. Familia y vida privada en Chile y el medio rural en la segunda mitad del siglo $X X$. Santiago de Chile: LOM/Universidad de Santiago de Chile.

Ídem (1988), "La feminización del mercado de trabajo agrícola en Chile Central”. En: Mundo de Mujer. Continuidad y cambio. Santiago: CEM.

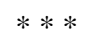

Recibido: 26.0.2011

Aceptado: 23.11.2011 